\title{
Close, but no cigar
}

\author{
M. Bishawi $\cdot$ C. Foppa $\cdot$ R. Bergamaschi
}

Received: 12 May 2014/ Accepted: 13 May 2014/Published online: 5 July 2014

(C) Springer-Verlag Italia Srl 2014

We read with interest the article by Formijne Jonkers et al. [1] entitled "Laparoscopic resection rectopexy versus laparoscopic ventral rectopexy for complete rectal prolapse." Although we understand the editors' good intention to provide timely contributions to the contemporary debate on ventral rectopexy (first described in the literature in 1960) [2], we feel compelled to note that the study unfortunately suffers from a number of major methodological limitations that make it difficult to draw any data-supported conclusions.

The first concern consists of the misrepresentation of the term cohort. The term, which historically referred to the basic unit of a Roman legion, nowadays is used to describe a population-based study that is analytical and observational. This differs from a case series, which is actually descriptive and experimental [3], thereby a more appropriate labeling of the article by Formijne Jonkers et al.

As can be quickly gleaned, the time frame for subject inclusion differed in the study arms, the number of patients in each study arm was determined arbitrarily, and the number of surgeons involved in performing the operations was not reported. In addition, the authors retrospectively scored the constipation/obstructed defecation syndrome using the Rome II criteria. The same was true for the fecal incontinence score. This can be because the chart reviewer and the medical record overall underreport individual components of these scales. In fact, these scores are validated when completed by the patient at a specific time. The scores have not been validated when completed by a reviewer (sometimes looking back over a decade in the medical chart) to gather information. These factors contribute to the risk of underestimating the actual score.

Conflict of interest None.

\section{References}

1. Formijne Jonkers HA, Maya A, Draaisma WA et al (2014) Laparoscopic resection rectopexy versus laparoscopic ventral rectopexy for complete rectal prolapse. Tech Coloproctol 18:641-646

2. Deucher F (1960) Ventral rectopexy in the treatment of rectal prolapse. Helv Chir Acta 27:240-246

3. Dekkers OM, Egger M, Altman DG, Vandenbroucke JP (2012) Distinguishing case series from cohort studies. Ann Intern Med 3:37-40
M. Bishawi · C. Foppa · R. Bergamaschi $(\bowtie)$

Division of Colorectal Surgery, State University of New York,

Stony Brook, NY, USA

e-mail: rcmbergamaschi@gmail.com 